\title{
Retained clamp after correct surgical counting: when risk factors count
}

Ricardo Bernardoㄹ ${ }^{\text {; }}$ Miguel Laires ${ }^{1}$; Joana Amorim¹; Patrícia Conde ${ }^{2}$

${ }^{1}$ Resident, Department of Anesthesiology ; ${ }^{2}$ Attending, Department of Anesthesiology

Hospital de Santa Maria - Centro Hospitalar Lisboa Norte - Lisbon, Portugal

BACKGROUND Retained surgical items (RSI) are completely preventable "never events" that can result in unnecessary patient morbidity, legal liability and increased health-care expenses. The reported incidence of RSI is $0.3-1.0$ per 1000 operations probably representing an underestimation of the real problem. A recent meta-analysis documented seven statistically significative RSI risk factors (Table 1). Other elements such as changes in nursing staff, emergency surgery, body-mass index and operation "afterhours" were not significantly associated with increased risk.,2
TABLE 1. RISK FACTORS FOR RETAINED SURGICAL INSTRUMENTS ${ }^{1}$ INTRAOPERATIVE BLOOD LOSS ABOVE $500 \mathrm{ML}$ DURATION OF OPERATION

MORE THAN ONE SUBPROCEDURE

UNEXPECTED INTRAOPERATIVE FACTORS

MORE THAN ONE SURGICAL TEAM

LACK OF SURGICAL COUNTS

INCORRECT SURGICALCOUNT

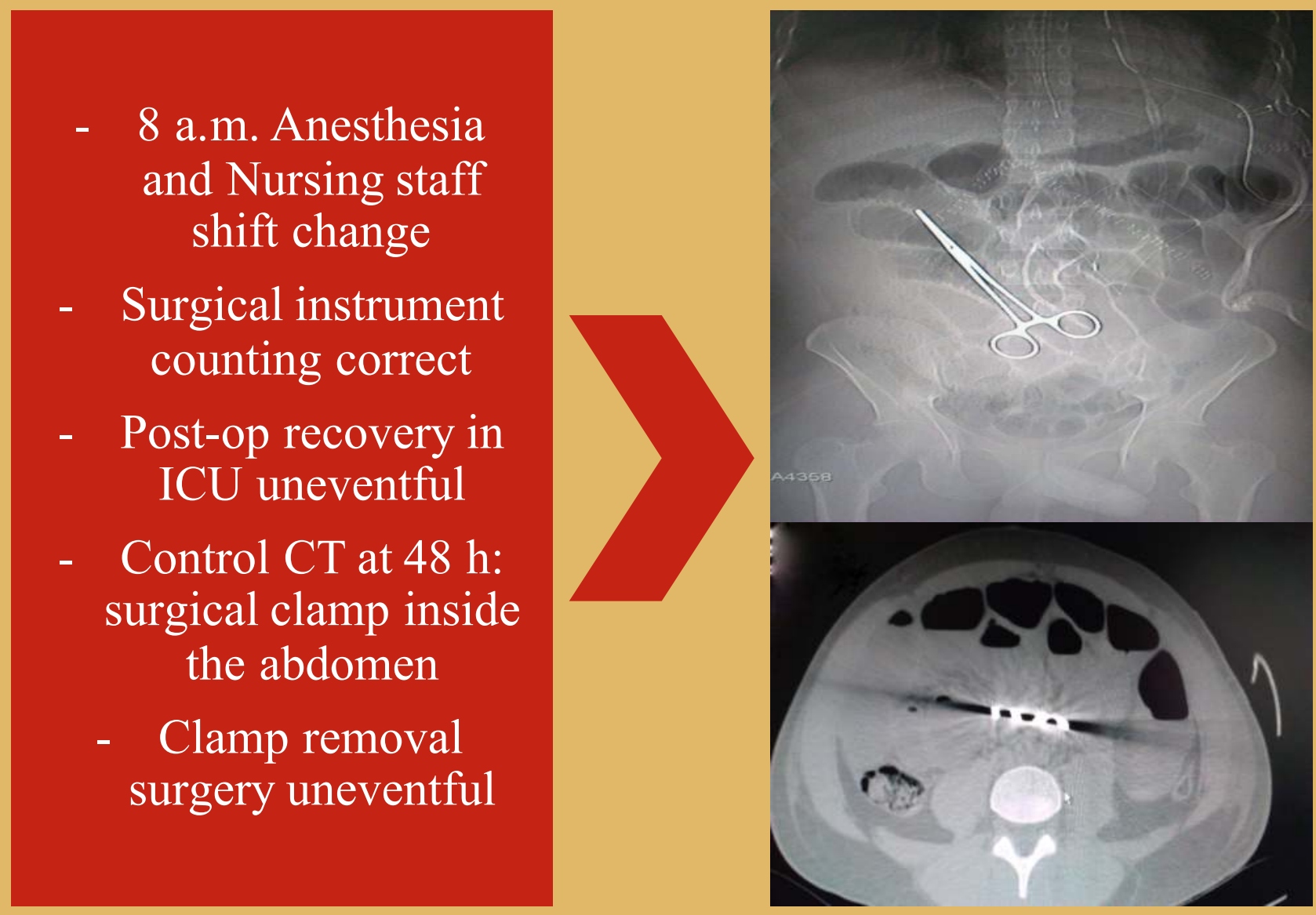

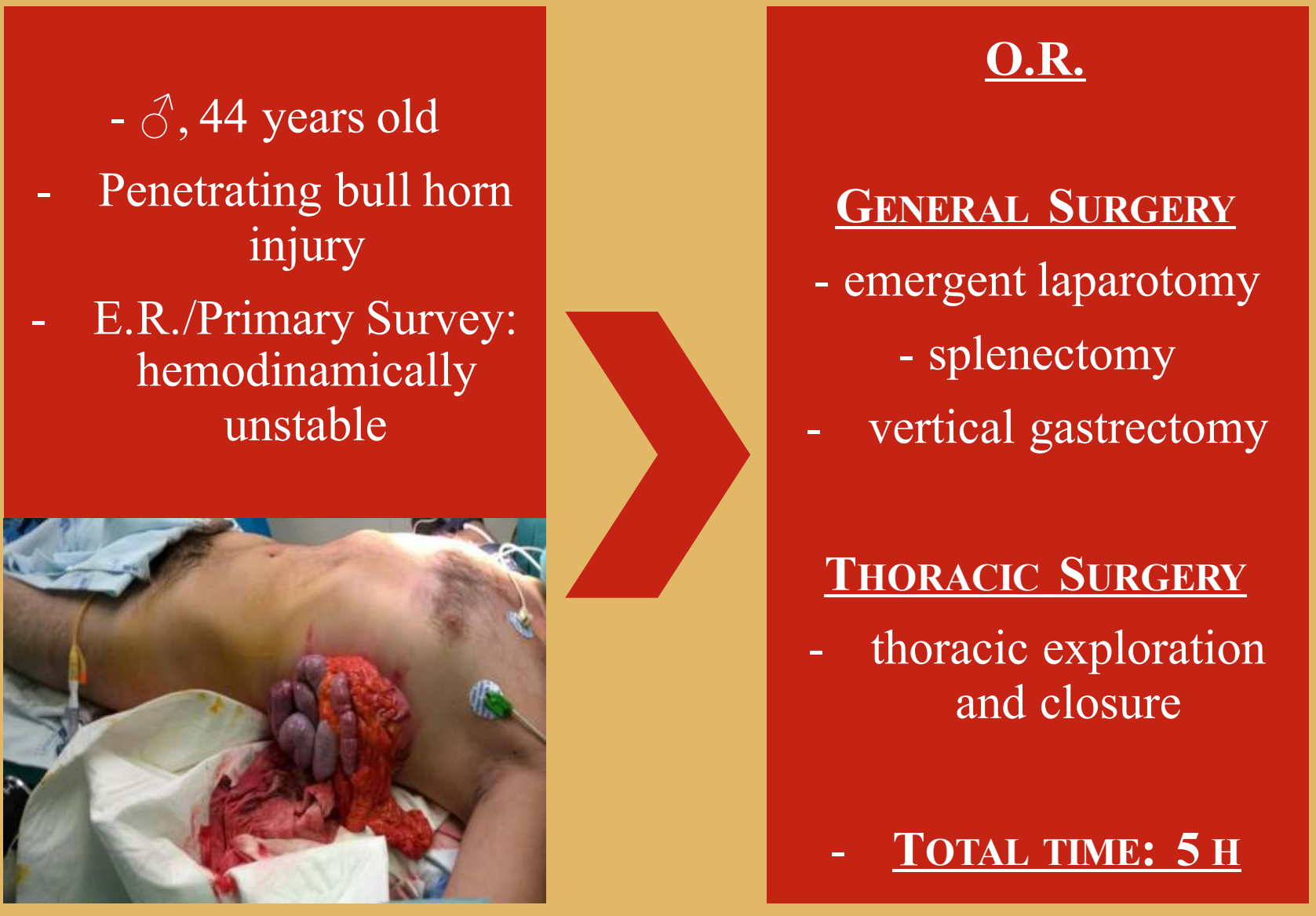

DISCUSSION This report illustrates a case of RSI in a surgery with an overall RSI high risk profile (at least 5 risk factors identified) and despite correct surgical instruments counting. The reported sensitivity of this method in preventing these events is only $77 \% .^{3}$

RSI risk stratification is crucial and should be evaluated in every surgery. Complementary preventive strategies (traditional and computer assisted barcoded surgical counts, radiographic verification, radiofrequency labeling of instruments and sponges) can be adopted and individually tailored to the calculated risk.

\section{LEARNING PoInTS}

A RSI represents a surgical patient safety problem whose prevention requires knowledge, shared information between all perioperative personnel and practice change.

Future investigation is needed in order to evaluate the real incidence of this problem and to validate a RSI risk score.

A surgical RSI risk stratification should be included in the OR checklist in order to apply the adequate differential preventive strategies.

It is critical to emphasize the need for a multidisciplinary approach and paradigm shift inside the operating room to turn a "never event" into a "never happen event".

REFERENCES:

1. Moffatt-Bruce SD. J Surg Res 2014;190:429-36.

2. Hempel S, et al. JAMA Surg 2015;150(8):796-805.

3. Egorova NN et al. Ann Surg 2008; 247(1):13-8. 